\title{
Glycemic index of cracked corn, oat groats and rolled barley in horses ${ }^{1}$
}

\author{
E. Jose-Cunilleras**2, L. E. Taylor ${ }^{*}$, and K. W. Hinchcliff* \\ *The Ohio State University, Department of Veterinary Clinical Sciences, Columbus 43210; and \\ †Otterbein College, Department of Equine Science, Westerville, OH 43081
}

\begin{abstract}
Muscle glycogen synthesis depends on glucose availability. This study was undertaken to determine the glycemic and insulinemic response of horses to equal amounts of hydrolyzable carbohydrates (starch and sugar) in the form of one of three grain meals or intragastric administration of a glucose solution. In a randomized crossover design, seven horses were fed each of three grain meals (cracked corn, steamed oat groats, or rolled barley) or were infused intragastrically with glucose solution at $2 \mathrm{~g}$ of hydrolyzable carbohydrate (starch plus sugar) per kilogram of BW. The quantity of hydrolyzable carbohydrate ingested was not different among all treatments $(P=$ 0.70 ). Plasma glucose concentration peaked in all four treatments by 1.5 to $2 \mathrm{~h}$ after feeding. Plasma glucose concentration remained higher than baseline in oat groats or barley-fed horses throughout $8 \mathrm{~h}$, whereas
\end{abstract}

plasma glucose returned to baseline by 5 to $6 \mathrm{~h}$ in cornfed horses or after glucose administration. Meal consumption was slower in oat groats-fed horses than in corn-fed ones, which may confound the glycemic and insulinemic responses observed after grain feeding. Plasma glucose area under the curve (AUC) was $63 \%$ both in corn and oat groats and $57 \%$ in barley-fed horses compared with that of horses administered glucose $(P=$ 0.13). Serum immunoreactive insulin concentration peaked between 2 and $3 \mathrm{~h}$ after feeding or glucose administration, and barley-fed horses had lower serum immunoreactive insulin concentration by 3 to $4 \mathrm{~h}$ than corn-fed horses or after glucose administration $(P<$ 0.05 ). We conclude, in horses, ingestion of oat groats, corn, and barley result in similar plasma glucose AUC and, compared with the glycemic index of 100 as the glucose reference, corn, oat groats, and barley had a glycemic index of approximately 60 .

Key Words: Feed Grains, Glucose, Horses, Starch

c)2004 American Society of Animal Science. All rights reserved.

J. Anim. Sci. 2004. 82:2623-2629

\section{Introduction}

The glycemic index concept was developed in human nutrition in an attempt to characterize foods according to their postprandial glycemic response rather than their chemical composition (Jenkins et al., 1981). The glycemic effect of a food in humans is influenced by the nature of the starch granules, the type of carbohydrates, the physical form of the food, and processing (Wolever, 1990).

Energy intake of horses is primarily from carbohydrates in forages and grains. The majority of starch and sugar ingested is digested in the small intestine of hindgut fermenters and absorbed as monosaccharides.

\footnotetext{
${ }^{1}$ We thank L. Avila for her technical assistance. This study was supported by grants from Grayson-Jockey Club Research Foundation, Inc., and Buckeye Feed Mills, Inc.

${ }^{2}$ Correspondence: Veterinary Teaching Hospital, 601 Vernon L. Tharp St. (phone: 614-292-6661; fax: 614-688-5642; e-mail: jose-cunilleras.1@osu.edu).

Received October 16, 2003

Accepted May 17, 2004.
}

Grains commonly fed to horses (oats, corn, and barley) contain on average 45 to $65 \%$ nonstructural carbohydrate (NSC) on an as-fed basis (50 to $73 \%$ on a DM basis; NRC, 1989). Corn has a greater starch content than oats or barley (Borggreve et al., 1975; Murray et al., 2001). In horses, oat starch has been more digestible than cornstarch in some (Meyer et, al., 1993; 1995), but not all (Potter et al., 1992), studies.

Digestion of starch and sugar in feedstuffs provides most of the substrate required for muscle glycogen synthesis after exercise. The rate of muscle glycogen replenishment after exercise in humans and horses depends on glucose availability (Ivy et al., 1988; Lacombe et al., 2001). Because of inherent differences in grains commonly fed to horses, the availability of glucose after ingestion of a grain meal may differ, which may affect muscle glycogen synthesis and athletic performance.

The current study was undertaken to determine the glycemic and insulinemic response of horses to ingestion of equal amounts of hydrolyzable carbohydrates in the form of one of three grain meals (cracked corn, steamed oat groats, or rolled barley), or intragastric administration of glucose. We hypothesized that oat 
Table 1. Feed analysis of mixed hay and grains (as-fed basis, with DM basis values in parentheses) ${ }^{a}$

\begin{tabular}{lcccc}
\hline \hline Item, $\%$ & Cracked corn & Oat groats & Rolled barley & Mixed hay \\
\hline DM & 85.9 & 87.1 & 88.0 & 87.7 \\
CP & $7.2(8.3)$ & $13.9(15.9)$ & $10.1(11.5)$ & $15.5(17.7)$ \\
ADF & $5.0(5.9)$ & $6.5(7.4)$ & $6.8(7.8)$ & $27.9(31.8)$ \\
NDF & $9.6(11.2)$ & $9.7(11.1)$ & $18.9(21.5)$ & $39.3(44.8)$ \\
Lignin & $0.4(0.5)$ & $1.8(2.0)$ & $1.9(2.1)$ & $3.9(4.4)$ \\
Starch & $60.5(70.3)$ & $46.8(53.7)$ & $46.7(53.0)$ & $3.8(4.3)^{*}$ \\
Sugar & $1.1(1.3)$ & $1.0(1.2)$ & $1.1(1.3)$ & - \\
NSC & $64.0(74.5)$ & $55.3(63.5)$ & $54.1(61.5)$ & $25.0(28.5)$ \\
Crude fat & $3.7(4.3)$ & $5.9(6.8)$ & $2.5(2.8)$ & $2.4(2.7)$ \\
Ash & $1.5(1.7)$ & $2.4(2.7)$ & $2.5(2.8)$ & $7.9(9.0)$ \\
TDN & $75.9(88.3)$ & $77.2(88.7)$ & $69.6(79.1)$ & $48.3(55.0)$ \\
DE, Mcal/kg & $3.23(3.76)$ & $3.35(3.85)$ & $2.94(3.49)$ & $2.13(2.42)$ \\
\hline
\end{tabular}

"Analyzed by Cumberland Valley Analytical Services, Inc. (Maugansville, MD).

${ }^{b}$ Nonstructural carbohydrate (NSC $=100-\mathrm{CP}-\mathrm{NDF}-$ crude fat - ash).

groats would have higher glucose availability than corn and barley in horses, when assessed as the glycemic index compared with oral glucose.

\section{Materials and Methods}

\section{Aninals}

Seven (three geldings and four mares) 4- to 11-yr-old Thoroughbred horses, with an average BW of $484 \pm 17$ $\mathrm{kg}$ average $( \pm \mathrm{SE})$, and BCS of 4 to 5 out of 9 , were used in this study (Henneke et al., 1983). The horses had been trained $3 \mathrm{~d} / \mathrm{wk}$ for $6 \mathrm{wk}$ and were part of an exercise physiology study. Exercise consisted of $30 \mathrm{~min}$ of trotting at 4 to $4.5 \mathrm{~m} / \mathrm{s}$ with the treadmill set at $4^{\circ}$ incline. Horses were fed mixed hay and cracked corn (Table 1) to meet energy requiremonts described by the NRC guidelines for horses in a moderate-intensity exercise program before the study (NRC, 1989). The diet consisted of $11 \mathrm{~kg}$ of mixed hay and $2.8 \mathrm{~kg}$ of corn daily, fed in two equal portions (as-fed basis). Horses were kept in $3 \times 4 \mathrm{~m}$ stalls and had access to water and a trace mineral salt block (iOFIXT, Morton Int., Inc., Chicago, IL) at all times. Experiments were performed in compliance with the guidelines and recommendations of the Institutional Laboratory Animal Care and Use Committee of The Ohio State University.

\section{Experimental Protocol}

Horses were used in a randomized crossover design. Each of seven horses was studied on four occasions and randomly assigned to a treatment (glucose, corn, oat groats, and barley). The study was conducted during a 2 -wk period, and between trials, each horse had at least a 2-d washout period, during which they were fed their regular dict (mixed hay and corn). Two weeks before the beginning of the study, the horses were adjusted to feed containing oat groats and rolled barley to familiarize them with all grains used during the study.

In each trial, following an 18-h feed withdrawal, horses were offered a meal of cracked corn, stcamed oat groats, or rolled barley, or were administered a $50 \%$ (wt/vol) glucose solution by nasogastric intubation. All four treatments were designed to provide $2 \mathrm{~g}$ of available carbohydrate $/ \mathrm{kg}$ of $\mathrm{BW}$. Available carbohydrate was considered to be $100 \%$ for glucose solution, and the summation of starch and sugar for grains (Table 1). The amounts of corn, oat groats, and barley offered to these horses were $1.5 \pm 0.1,1.9 \pm 0.1$, and $1.9 \pm 0.1 \mathrm{~kg}$ (mean $\pm \mathrm{SE}$ ), respectively. Blood samples for determination of plasma glucose concentration were obtained via an indwelling jugular catheter before feeding, every 30 min for the first $4 \mathrm{~h}$ after feed was offered, and every $1 \mathrm{~h}$ for another $4 \mathrm{~h}$, whereas blood samples for determination of serum immunoreactive insulin (IRI) concentration were only obtained before feeding, every $60 \mathrm{~min}$ for the first $4 \mathrm{~h}$, and at 6 and $8 \mathrm{~h}$ after feeding. Horses were kept in a straw bedded stall and left undisturbed with the exception of blood collection. Horses were allowed to consume grain for a maximum of $3 \mathrm{~h}$ and remained muzzled until blood sample collection was complete $(8 \mathrm{~h})$. Unconsumed grain was removed and its weight recorded. Horses had access to water but no access to roughage during the entire 8-h trial.

Data from horses that did not consume more than $75 \%$ of the meal were not considered in the statistical analysis. One horse consumed only 62 and $28 \%$ of the oat groats and barley meals, respectively, and another horse consumed only $58 \%$ of the oat groats meal.

\section{Analytical Methods}

Blood samples were collected into tubes containing potassium oxalate and sodium fluoride for analysis of plasma glucose, and into tubes without additives for analysis of IRI. Within $10 \mathrm{~min}$ of collection, samples were centrifuged $(1,500 \times \mathrm{g})$ in a refrigerated centrifuge, and plasma and serum were collected and stored at $-80^{\circ} \mathrm{C}$ until analysis. Glucose analysis was performed using a spectrophotometric method based on glucose hexokinase (glucose hexokinase kit; Sigma Diagnostics, St. Louis, MO). Analyses were performed in duplicate, 
and all samples obtained from one horse were analyzed in a single session to avoid interassay variation. Intraand interassay CV were 5 and $6.5 \%$, respectively. Serum IRI was determined in duplicate by use of a commercially available RIA (Insulin kit; Coat-a-Count Diagnostics, Los Angeles, CA) validated for horse blood (Freestone et al., 1992). Intra- and interassay CV were $<10 \%$, and the limit of detection was $5.08, \mathrm{uIU} / \mathrm{mL}$.

Mixed grass/alfalfa hay and grains were analyzed in a commercial laboratory for nutrient composition, starch, and sugar content (Cumberland Valley Analytical Services, Inc., Maugansville, MD). Cracked corn, steamed oat groats, and rolled barley were analyzed enzymatically for starch (Holm et al., 1986) and for sugar using a solvent extraction and enzymatic analysis (Dubois et al., 1956) (Table 1). The total amount of starch and sugar was considered to be the total amount of carbohydrate available to the equine small intestine for absorption as mono- and disaccharides and eventual transformation to glucose. Digestible energy was calculated from NSC, available protein (AP; CP - ADF $\mathrm{CP}$ ), ether extract (EE), protein-free NDF (NDFpf), and lignin (Lig), using an equation based on the Weiss (1993) ruminant equation and adapted by Cupp (2000) to equine diets:

$$
\begin{gathered}
\mathrm{DE}, \mathrm{Mcal} / \mathrm{kg}=0.04409\{(0.9 \times \mathrm{NSC})+\mathrm{AP}+ \\
0.94[2.25 \times(\mathrm{EE}-1)]+0.35(\mathrm{NDFpf}-\mathrm{Lig}) \times \\
\left.\left[1-(\text { lig } / \mathrm{NDFpf})^{0.667}\right]\right\}
\end{gathered}
$$

\section{Statistical Analysis}

Data are presented as means and standard errors of the mean. Plasma glucose, serum IRI concentrations, and glucose:insulin ratios were analyzed using a mixed model with repeated measures with treatment, time, and the interaction of treatment and time as fixed effects, horse as random effect, and compound symmetry as the covariance structure (Milliken and Johnson, 1992; Steel et al., 1997). Pairwise comparisons of treatment effects (glucose vs. corn, glucose vs. oats, glucose vs. barley, corn vs. oats, corn vs. barley, and oats vs. barley) and pairwise comparisons of treatment means within each time point (six comparisons at 13 time points) were performed by the Dunn-Sidák multiplecomparisons procedure with adjusted $P<0.05$ (Ludbrook, 1991; Pedhazur, 1997). Areas under the concentration-time curve (AUC) were calculated by the trapezoidal method (Gibaldi and Perrier, 1982) for plasma glucose and serum IRI concentrations. The AUC obtained for the glucose treatment was considered to correspond to a glycemic index (GI) of 100 , and the three grains were given a GI based on their AUC expressed relative to the reference AUC of the glucose treatment. Areas under the curve, time of consumption of grain meals, and amount of starch and/or sugar ingested were compared by one-way ANOVA with repeated measures, with the significance level set at $P<0.05$. The Sigmastat 2.0 (Jandel Scientific, San Rafael, CA) and SPSS 12.0
(SPSS Inc., Chicago, IL) software packages were used for statistical computations.

\section{Results}

\section{Meal Consumption}

Average meal consumption was $97 \pm 2,95 \pm 3$, and $93 \pm 4 \%$ for corn, oat groats, and barley, respectively. The amounts of hydrolyzable carbohydrates (starch plus sugars) ingested from corn, oat groats, and barley were $921 \pm 37,946 \pm 65$, and $869 \pm 56 \mathrm{~g}$, respectively. The quantity of glucose administered intragastrically was $939 \pm 33 \mathrm{~g}$. There was no difference among the four treatments in the combined amount of starch and sugar ingested $(P=0.7)$. The amount of $\mathrm{DE}$ provided was 4.8 $\pm 0.2,5.7 \pm 0.4$, and $5.4 \pm 0.3$ Mcal for corn, oat groats, and barley, respectively. There was no difference among treatments in the amount of DE ingested $(P=0.10)$. The time needed to consume the entire meal or removal of the leftover grains was $50 \pm 14,126 \pm 19$, and $78 \pm$ $25 \mathrm{~min}$ for corn, oat groats, and barley, respectively. The time needed to consume each meal was significantly longer for oat groats than for corn $(P=0.013)$.

\section{Glycemic Response}

Mean plasma glucose concentrations before treatments ranged from 4.1 to $4.5 \mathrm{~m} M$. Plasma glucose concentrations peaked with all four treatments at 1.5 to 2 $\mathrm{h}$ after offering the meal or administering glucose (Figure 1). In horses fed corn or administered glucose solution, plasma glucose concentrations at 5 to $6 \mathrm{~h}$ after feeding were similar to those before feeding. In contrast, horses fed oat groats or barley continued to have elevated plasma glucose concentrations $6 \mathrm{~h}$ after feeding (Figure 1). Plasma glucose concentrations were greater in horses given glucose than in corn-fed and oat-fed horses $(P<0.001)$, and tended to be higher in horses given glucose compared with barley-fed horses $(P=$ 0.09 ). Specifically, plasma glucose concentrations were higher at 90,120 , and $150 \mathrm{~min}$ in horses given glucose than in oat-fed horses $(P<0.028)$, and at $240 \mathrm{~min}$ in horses given glucose vs. corn-fed horses $(P=0.032)$.

Area under the glucose concentration-time curve for horses given glucose, corn, oat groats, and barley were $818 \pm 170,519 \pm 106,514 \pm 43$, and $468 \pm 42 \mathrm{mM} \cdot \mathrm{min}$, respectively, and were not statistically different $(P=$ 0.22 ). Glucose AUC adjusted for hydrolyzable carbohydrate ingestion in horses given glucose, corn, oats, and barley were $818 \pm 170,529 \pm 108,510 \pm 38$, and $505 \pm$ $40 \mathrm{mM} \cdot \mathrm{min}$, respectively. When the glycemic index of the glucose reference treatment was set to 100 , the corresponding glycemic indices for corn, oat groats, and barley were 63,63 , and 57 , respectively. The glycemic indices adjusted for hydrolyzable carbohydrate ingestion for corn, oat groats, and barley were 65,62 , and 62 , respectively. 


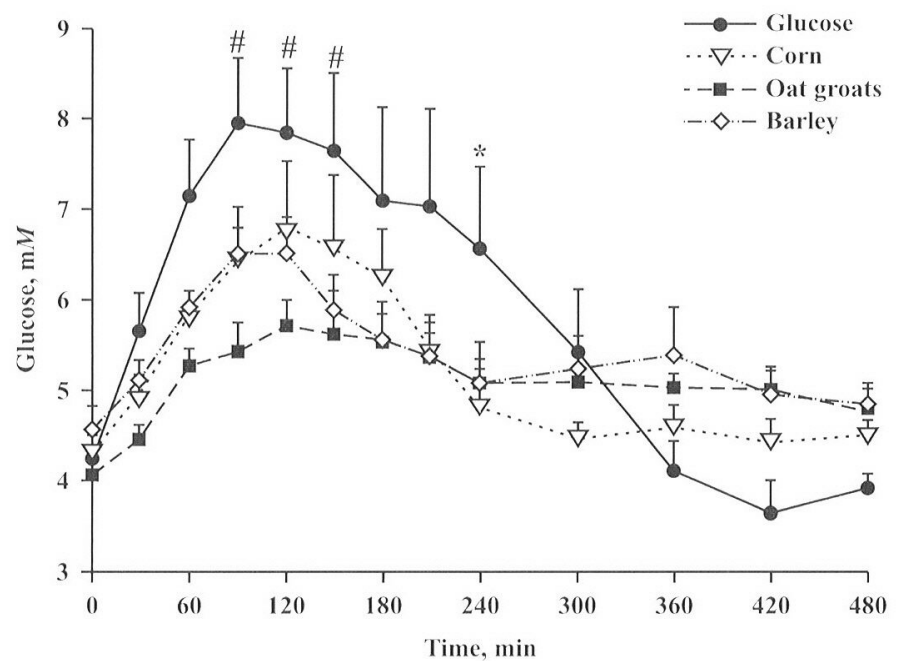

Figure 1. Plasma glucose concentration $(\mathrm{m} M)$ immediately before and during the $8 \mathrm{~h}$ after ingestion of $2 \mathrm{~g} / \mathrm{kg}$ BW of starch and sugar in the form of cracked corn, oat groats, rolled barley, or administration of glucose. Horses were fed right after $0 \mathrm{~min}$ and muzzled after finishing each meal or at $180 \mathrm{~min}$ if not finished. Values are means \pm SE for seven horses (except oats [ $n=5]$, and barley [ $\mathrm{n}=$ 6]). Time points different among treatments: ${ }^{*}$ glucose vs. corn, $P=0.03$; \# glucose vs. oat groats, $P<0.03$. Treatment effect $(P=0.001)$ : glucose vs. corn, $P<0.001$; glucose vs. oats, $P<0.001$; glucose vs. barley, $P=0.09$. Time effect: $P<0.001$. Time $\times$ treatment interaction: $P=0.004$.

\section{Insulinemic Response}

Serum immunoreactive insulin concentrations before feeding or glucose administration were below the limit of detection $(<5.08 \mu \mathrm{IU} / \mathrm{mL})$. Serum IRI concentrations peaked in horses receiving all four treatments at 2 to $3 \mathrm{~h}$ after offering the meal or given glucose (Figure 2). Serum IRI concentrations declined gradually from 4 to $8 \mathrm{~h}$ in all four treatments. Serum IRI concentrations were lower in horses fed barley compared with horses fed oat groats $(P=0.006)$ and horses given glucose $(P=0.009)$. Specifically, serum IRI concentrations were lower at $180 \mathrm{~min}$ in barley-fed horses than in corn-fed horses $(P=0.03)$, and after glucose administration ( $P=$ 0.001 ) and at $240 \mathrm{~min}$ in barley-fed horses compared with those given glucose $(P=0.001)$.

Area under the serum IRI concentration-time curves for horses receiving glucose, corn, oats, and barley treatments were $7,860 \pm 2,342,5,637 \pm 1,430,5,314 \pm 1,379$ and $3,030 \pm 502 \mu \mathrm{IU} \cdot \mathrm{min}^{-1} \cdot \mathrm{mL}^{1}$, respectively. Barleyfed horses tended to have lower serum IRI AUC compared with other treatments $(P=0.06)$. Serum IRI AUC adjusted for hydrolyzable carbohydrate ingestion in horses given glucose, corn, oats, and barley were 7,860 $\pm 2,032,5,747 \pm 1,315,5,275 \pm 1,526$, and $3,274 \pm 513$ $\mu \mathrm{IU} \cdot \mathrm{min}^{1} \cdot \mathrm{mL}{ }^{1}$, respectively.

The plasma glucose:serum IRI ratios decreased from values greater than 0.7 to 0.9 before feeding or glucose

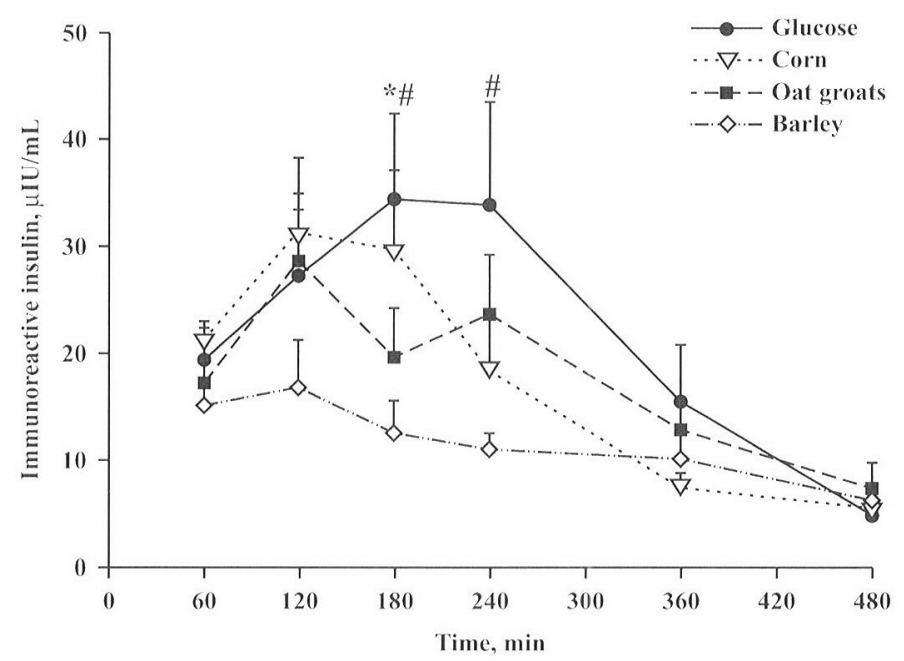

Figure 2. Serum immunoreactive insulin concentration immediately before and during the $8 \mathrm{~h}$ after ingestion of $2 \mathrm{~g} / \mathrm{kg}$ BW of starch and sugar in the form of cracked corn, oat groats, rolled barley, or administration of glucose. Values are means \pm SE for seven horses (except oats $[n=5]$, and barley $[n=6])$. Values are not reported at $0 \mathrm{~min}$ because insulin concentrations were below the detection limit $(<5.08 \mu \mathrm{IU} / \mathrm{mL})$. Time points different among treatments: *glucose vs. barley, $P=0.001$; \# corn vs. barley, $P=0.03$. Treatment effect $(P<0.001)$ : glucose vs. barley, $P=0.009$; oats vs. barley, $P=0.006$. Time effect: $P<0.001$. Time $\times$ treatment interaction: $P=0.02$.

administration to approximately 0.25 to 0.4 during the following $4 \mathrm{~h}$ (Figure 3 ). Glucose:IRI ratios were higher in barley-vs. corn-fed horses $(P=0.03)$ or oat-fed horses $(P=0.001)$ and after administration of glucose $(P=$ 0.005 ). Specifically, glucose:IRI ratios were higher at $120 \mathrm{~min}$ in barley-fed horses than in oat-fed horses $(P=$ $0.04)$, and at $180 \mathrm{~min}$ in barley-fed horses than in cornfed horses $(P=0.03)$ and after glucose administration $(P=0.04)$.

\section{Discussion}

The current study examined the glycemic and insulinemic response to a meal of cracked corn, steamed oat groats, and rolled barley that provided approximately equal amounts of starch and sugars and compared these to intragastric administration of an equal amount of glucose. The main findings were 1) plasma glucose concentration peaked in all four interventions by 1.5 to 2 $h$ after the onset of grain ingestion or glucose administration; 2) compared with plasma glucose AUC of horses administered glucose, plasma glucose AUC were approximately 57 to $63 \%$ in grain-fed horses; however, these differences did not reach statistical significance $(P=0.22)$; and 3$)$ of the three grains studied, ingestion of corn resulted in the largest fluctuations in plasma glucose.

To our knowledge, this is the first study performed in horses to describe the glycemic and insulinemic re- 


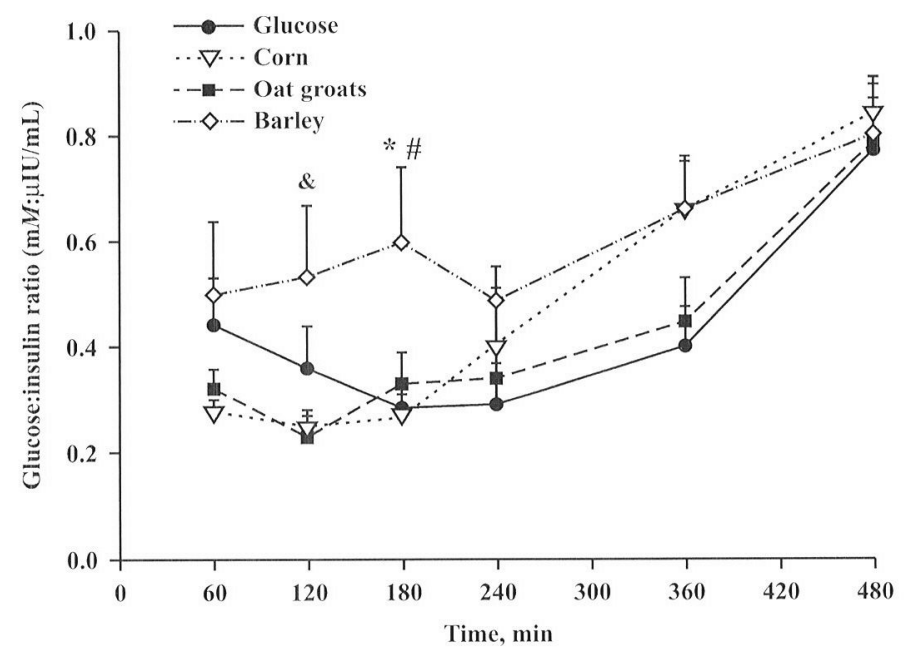

Figure 3. Glucose:insulin ratios after ingestion of $2 \mathrm{~g} /$ $\mathrm{kg} \mathrm{BW}$ of starch and sugar in the form of cracked corn, oat groats, rolled barley, or administration of glucose. Values are means \pm SE for seven horses (except oats $[\mathrm{n}=$ $5]$, and barley $[\mathrm{n}=6])$. Values are not reported at $0 \mathrm{~min}$ because insulin concentrations were below the detection limit $(<5.08 \mu \mathrm{IU} / \mathrm{mL})$. Time points different among treatments: *glucose vs. barley, $P=0.04$; \# corn vs. barley, $P=$ 0.03 ; \& oats vs. barley, $P=0.04$. Treatment effect $(P<$ 0.001): glucose vs. barley, $P=0.005$; oats vs. barley, $P=$ 0.001; corn vs. barley, $P=0.03$. Time effect: $P<0.001$. Time $\times$ treatment interaction: $P=0.30$.

sponse of feeding different grain meals that provide an approximately equal amount of starch and sugar content and to compare these to intragastric administration of an equivalent amount of glucose. This approach is similar to that of studies performed in human nutrition, in which the GI of foods is determined by serial measurement of plasma glucose concentration after ingestion of equal amounts of digestible carbohydrate in a food compared with a reference of glucose solution or white bread (Jenkins et al., 1981; Wolever, 1990).

Previous studies performed in horses have compared the effect of ingestion of varying amounts of grains or concentrates on plasma glucose and serum insulin concentrations (Ralston, 1992; Stull and Rodiek, 1988; Pagan et al., 1999; Williams et al., 2001). These studies showed that ingestion of grains, concentrates, and/or roughage meals results in moderate to marked hyperglycemia and hyperinsulinemia 1 and $3 \mathrm{~h}$ after eating. However, these studies compared ingestion of different grains or concentrates as equal weight or isocaloric meals, which did not result in ingestion of equal amounts of starch and sugar. In addition, these studies did not perform a reference intervention, such as administration of an equal amount of completely available carbohydrate.

The GI provides a way to classify carbohydrate-rich foods according to the magnitude of the glycemic re- sponse following intake (Jenkins et al., 1981). Using a more physiologically based classification of foods based on the GI, dietetic strategies have been developed for human athletes and noninsulin-dependent diabetics. In human athletes, ingestion of high-GI foods after exercise results in greater synthesis of muscle glycogen (Burke et al., 1993) compared with ingestion of equal amounts of carbohydrates as low-GI foods. In contrast, ingestion of low-GI foods before exercise in endurance athletes may attenuate the insulin-mediated metabolic disturbances and may lead to more sustained carbohydrate availability (Thomas et al., 1991). Similarly, lowGI diets have been shown to improve glycemic control in noninsulin-dependent diabetics and to reduce serum lipids in hyperlipidemic subjects (Jenkins et al., 2002). Lower insulin sensitivity has been demonstrated in inactive and obese horses (Powell et al., 2002; Hoffman et al., 2003), and it has been proposed to play a role in the undefined syndrome referred to as equine metabolic syndrome or equine peripheral cushingoid syndrome (Johnson, 2003). Description of the GI of horse feeds is a prerequisite to defining dietetic strategies useful for athletic horses and those afflicted with clinical conditions related to lack of insulin sensitivity.

The magnitude of the glycemic response to ingestion of a carbohydrate-rich meal reflects the rate of digestion and absorption. In the case of grains commonly fed to horses, starch makes up most of the carbohydrate; therefore, inherent differences in starch digestibility among grains may be reflected as different GI. Several studies using horses or ponies with ileal or cecal fistulae have determined that small intestinal starch digestibility depends on its botanical origin and prior physical or thermal treatment. However, there is conflicting evidence for the difference in small intestinal starch digestibility between grains commonly fed to horses. Several studies have shown that corn has a lower small intestinal starch digestibility (29 to $45 \%$ depending on prior processing) than oat starch ( 80 to $99 \%$ ) or barley starch $(81 \%$ ) (Meyer et al., 1993; 1995; De Fombelle et al., 2001). However, other studies indicated that starch digestibility was not different between corn (80\%), oats $(81 \%)$, and barley $(95 \%)$ (Potter et al., 1992) and between corn (71\%) and oats (98\%) (Radicke et al., 1991). In addition, alteration of the structure of cornstarch granules by grinding or thermal treatment significantly increases small intestinal digestibility (Meyer et al., 1995; Keinzle et al., 1997; Hoekstra et al., 1999). Despite possible differences in starch digestibility between different grains observed in previous studies, the glycemic response assessed as the glucose AUC did not differ among the corn, oat groats, and barley in the current study.

One limitation of this study is the fact that the rate of ingestion was unequal among the grains. Despite familiarization with ingestion of all three grains for 2 wk before the study, it took twice as long for these horses to eat an oat groats meal as it did a meal of cracked corn. The shape of the glycemic responses after 
glucose administration and corn ingestion were similar and secmed to have larger fluctuations in plasma glucose compared with oats and barley. This effect may be related to a slower rate of ingestion of oat groats and barley compared with corn. We suggest that some of the differences related to the rate of ingestion should be accounted for by calculation of glucose AUC and the prolonged period of blood collection.

The upper limit of small intestinal starch digestibility in horses has previously been reported to be 0.2 to $0.4 \%$ of BW per feeding (Potter et al., 1992; Meyer et al., 1995). The starch and sugar ingestion in this study was $0.19 \pm 0.01 \%$ of $\mathrm{BW}$, and no adverse effects were observed.

\section{Implications}

Horses are fed grains after exercise to meet energy requirements and provide substrate for muscle glycogen replenishment. This study showed that ingestion of three different grains (cracked corn, steamed oat groats and rolled barley) at approximately equal levels of starch plus sugar intake resulted in similar glycemic responses (assessed as glucose area under the curve over time). In addition, the magnitude of glycemic responses after ingestion of grains was approximately $60 \%$ of that after administration of an equivalent amount of glucose in the stomach. Characterization of grains commonly fed to horses according to their glycemic response may serve to develop nutritional strategies intended to maximize glucose availability (as in athletic horses for muscle glycogen synthesis) or when intending to minimize fluctuations in plasma glucose (as in clinical conditions suspected to be associated with a lack of insulin sensitivity in horses).

\section{Literature Cited}

Borggreve, G. J., G. J. van Kempen, J. P. Cornelissen, and A. H. Grimbergen. 1975. The net energy content of pig feeds according to the rostock formula the value of starch in the feed. $Z$. Tierphysiol. Tierernachr. Futtermittelkd 34:199-204.

Burke, L. M., G. R. Collier, and M. Hargreaves. 1993. Muscle glycogen storage after prolonged exercise: Effect of the glycemic index of carbohydrate feedings. J. Appl. Physiol. 75:1019-1023.

Cupp, C. 2000. How to determine energy in horse diets. Feed Manag. $51: 17-18$.

De Fombelle, A., P. Frumhollz, D. Poillion, C. Drogoul, C. Phillipeau, E. Jacotot, and V. Julliand. 2001. Effect of the botanical origin of starch on its prececal digestibility measured with the mobile bag technique. Pages 153-155 in Proc. 17th Equine Nutr. and Physiol. Symp. Equine Nutr. and Physiol. Soc., Savoy, II.

Dubois, M., K. A. Gilles, J. K. Hamilton, P. A. Robers, and F. Smith. 1956. Colorimetric method for determination of sugars and related substances. Anal. Chem. 28:350-356.

Freestone, J. F., K. Shoomaker, R. Bessin, and J. K. Wolfsheimer. 1992. Insulin and glucose response following oral glucose administration in well-conditioned ponies. Equine Vet. J. 11(Suppl): 13-17.

Gibaldli, M., and D. Perrier. 1982. Pharmacokinetics. 2nd rew. ed. Marcel Dekker, New York.
Henneke, D. R., G. D. Potter, J. I. Kroider, and B. F. Yeates. 1983 Relationship between condition score, physical measurements and body fat percentage in mares. Equine Vet. J. 15:37 1-372.

Hoekstra, K. E., K. Newman, M. $\Lambda$. P. Kennedy, and J. D. Pagan 1999. Effect of corn processing on glycemic response in horses Pages 144-148 in Proc. 16th Equine Nutr. and Physiol. Symp. Equine Nutr. and Physiol. Soc., Savoy, IJ.

Hoffman, R. M., R. C. Boston, D. Stefanovski, D. S. Kronfeld, and P. A. Harris. 2003. Obesity and diet affect glueose dynamics and insulin sensitivity in thoroughbred geldings. J. Anim. Sci. 81:2333-2342.

Holm, J., I. Björck, A. Drews, and N.-G. Asp. 1986. A rapid method for the analysis of starch. Starch [Staerkel 7:224-226.

Ivy, J. L., A. L. Katz, C. I. Cutler, W. M. Sherman, and F. F. Coyle 1988. Muscle glycogen synthesis after exercise: Fiffect of time of carbohydrate ingestion. J. Appl. Physiol. 64:1480-1485.

Jenkins, D. J., C. W. Kendall, L. S. Augustin, S. Franceschi, M. Hamidi, A. Marchie, A. L. Jenkins, and M. Axelsen. 2002. Glycemic index: Overview of implications in health and disease. Am. J. Clin. Nutr. 76:266s-273S.

Jenkins, D. J., T. M. Wolever, R. M. Taylor, H. Baker, H. Fielden, J. M. Baldwin, A. C. Bowling, H. C. Newman, A. I. Jenkins, and D. V. Goff. 1981. Glycemic index of foods: A physiological basis for carbohydrate exchange. Am. J. Clin. Nutr. 34:362-366.

Johnson, P. J. 2003. Peripheral cushingoid syndrome ('equine metabolic syndrome'). Pages 812-816 in Current Therapy in Equine Medicine. N. E. Robinson, ed. W. B. Saunders, Philadelphia, PA.

Keinzle, E., J. Pohlenz, and S. Radicke. 1997. Morphology of'starch digestion in the horse. Zentbl. Vetmed. Reihe A 44:207-221.

Lacombe, V. A., K. W. Hincheliff, R. J. Geor, and C. R. Baskin. 2001. Muscle glycogen depletion and subsequent replenishment affect anaerobic capacity of horses. J. Appl. Physiol. 91:1782-1790.

I udbrook, J. 1991. On making multiple comparisons in clinical and experimental pharmacology and physiology. Clin. Exp. Pharmacol. Physiol. 18:379-392.

Meyer, H., S. Radicke, E. Kienzle, S. Wilke, and D. Klefken. 1993. Investigations on preileal digestion of oats, corn, and barley starch in relation to grain processing. Pages 92-97 in Proc. 13th Equine Nutr. and Physiol. Symp. Equine Nutr. and Physiol Soc., Savoy, II.

Meyer, H., et al. 1995. Investigations on preileal digestion of starch from grain, potato and manioe in horses. Zentbl. Vetmed. Reihe A $42: 371-381$.

Milliken, C. A., and D. E. Johnson. 1992. Analysis of Messy Data. Van Nostrand Reinhold, New York.

Murray, S. M., E. A. Flickinger, A. R. Patil, N. R. Merchen, J. L. Brent, Jr., and G. C. Fahey, Jr. 2001. In vitro fermentation characteristics of native and processed cereal grains and potato starch using ileal chyme from dogs. J. Anim. Sci. 79:435-144.

NRC. 1989. Nutrient Requirements of Horses. 5th rev. ed. Natl. Acad. Press, Washington, $D C$.

Pagan, J. D., P. A. Harris, M. A. P. Kennedy, N. Davidson, and K. E. Hoekstra. 1999. Feed type and intake affects glycemic response in thoroughbred horses. Pages $149-150$ in Proc. 16th Equine Nutr. and Physiol. Symp.

Pedhazur, E. J. 1997. Multiple Regression in Behavioral Rosearch: Explanation and Prediction. 3rd ed. Harcourt Brace Colloge Publishers, Fort Worth, 'TX.

Potter, G. D., F. F. Arnold, D. D. Householder, G. II. Hansen, and K. M. Brown. 1992. Digestion of starch in the small or large intestine of the equine. Pages 107-111 in Proc. Ist Eur. Conf. Horse Nutr. Pferdeheilkunde, Sonderausgabe, Germany.

Powell, D. M., S. E. Reedy, D. R. Sessions, and B. P. Fitzgerald. 2002. Effect of short-term exercise training on insulin sensitivity in obese and lean mares. Equine Vet. J. (Suppl. 34): 81-84.

Radicke, S., F. Kienzle, and H. Meyer. 1991. Preileal apparent digestibility of oats and corn stareh and consequences for cecal metabolism. Pages 43-48 in 12th Equine Nutr. and Physiol. Symp. Equine Nutr. and Physiol. Soc., Savoy, lT.

Ralston, S. I. 1992. Effect of soluble carbohydrate content of polleted diets on postprandial glucose and insulin profiles in horses. Iferdehoilkunde 8:112-115. 
Steel, R. G. D., J. H. Torrie, and D. A. Dickey. 1997. Principles and Procedures of Statistics: A Biometrical Approach. 3rd ed. McGraw-Hill, New York.

Stull, C. L., and A. V. Rodiek. 1988. Responses of blood glucose, insulin and cortisol concentrations to common equine dicts. J. Nutr. 118:206-213.

Thomas, D. E., J. R. Brotherhood, and J. C. Brand. 1991. Carbohydrate feeding before exercise-effect of glycemic index. Int. $\mathrm{J}$. Sports Med. 12:180-186.
Weiss, W. P. 1993. Symposium: Prevailing concepts in energy utilization by ruminants. Predicting energy values of feeds. J. Dairy Sci. 76:1802-1811.

Williams, C. A., D. S. Kronfeld, W. B. Staniar, and P. A. Harris. 2001. Plasma glucose and insulin responses of thoroughbred mares fed a meal high in starch and sugar or fat and fiber. J. Anim. Sci. 79:2196-2201.

Wolever, T. M. 1990. The glycemic index. World Rev. Nutr. Dict. 62:120-185. 